\title{
Role of Tibialis Anterior Tendon Transfer Total or Split in Management of Relapsed Club Foot
}

\section{Mohamed Fathi Mohammed ${ }^{1, *}$ MSc., Bahaa Ali Kornah ${ }^{1}$ MD., Usama Gaber Abdalla ${ }^{1}$ MD.}

\author{
* Corresponding Author: \\ Mohamed Fathi Mohammed \\ mf656121@gmail.com
}

Received for publication March 10, 2021; Accepted April 30, 2021; Published online April 30, 2021.

Copyright 2020 The Authors published by Al-Azhar University, Faculty of Medicine, Cairo, Egypt. All rights reserved. This an openaccess article distributed under the legal terms, where it is permissible to download and share the work provided it is properly cited. The work cannot be changed in any way or used commercially.

doi: $10.21608 /$ aimj.2021.67144.1432

${ }^{1}$ Department of Orthopedic Surgery, Faculty of Medicine, Al-Azhar University, Egypt

\begin{abstract}
Background: Congenital club foot currently treated by Ponseti technique with excellent long-term outcome. However relapsed deformity developed due to non compliance of bracing wear, evertor, and invertor imbalance.

Aim of the work: to assess the ability of Prospective study are the full , and split tibialis anterior transfer can be correct relapsed club foot following Ponseti technique for idiopathic club foot.

Patients and Methods: This prospective study was planned to evaluate radiological and functional results of tibialis anterior tendon transfer for relapsed club foot deformity after Ponseti, in 16 patients with 20 feet ,the period of follow up was at least 6 months, The average age of the patients was 6 years, ranging from 3 to 9 years, 14 of them were males, 6 of them were females.

Result: Twenty operated on feet showed satisfactory results including 13 excellent cases and 7 good cases That satisfactory results were found in 20 patients $(100 \%)$, and no unsatisfactory ones. In this study, although there was significant improvement of, anterior talo first metatarsal angle (TFMA1) , and anterior talocalcaneal angle (Kite's angle) (TCA1) there was no significant correlation between radiological ,and functional end results. Tibialis anterior transfer has to be effective procedure in relapsed deformity, range of motion of foot and muscle function of children. Conclusion: Tibialis tendon transfer either total or split can effectively correct relapsed club foot after management by Ponseti technique.
\end{abstract}

Keywords: Club foot, Relapsed club foot, Total or split tibialis anterior tendon transfer.

Disclosure: The authors have no financial interest to declare in relation to the content of this article. The Article Processing Charge was paid for by the authors.

Authorship: All authors have a substantial contribution to the article.

\section{INTRODUCTION}

Currently idiopathic club foot treated by Ponseti technique with excellent outcome. The prevalence of clubfoot in 1000 live births there are 1 to 3 cases of club foot in Caucasians,girls affected half as often as boys and $20 \%$ of cases are bilateral. Most authors define "relapse" as any foot successfullycorrected by Ponseti and then relapsed and need another intervention. Incidence of relapse $26.6 \%$ to $50 \%$, the relapsed clubfoot may be stiff or flexible.

Management of relapsed club foot by total tendon transfer ${ }^{1}$ originally reported by Garceau $(1940),{ }^{2}$, and later modification done by Ponseti (1963), ${ }^{3}$ is described for the management of relapsed clubfoot management. Two types of tibialis anterior transfer are reported; whole tendon transfer ,and split tendon transfer. ${ }^{4}$

Stiff club foot can be treated by Ilizarov correction, hemiepiphysiodesis. We hypothesized relapsed club foot after successful management by Ponseti technique can be corrected by full and split tendon transfer. $5,3,6$

\section{PATIENTS AND METHODS}

This prospective study has been done in 20 patients in the orthopedic department Qena general hospital ,and Sayed Galal University Hospital .we had been taken a consent from patient's parents between December 2019 ,and January 2021,16 children with (20feet) . All of them had relapsed deformity following conservative treatment by Ponseti technique. 4 of them had bilateral affection , and 12 cases had unilateral affection .mean age 6 years range 3-9 years .inclusion criteria involved: Dynamic metatarsus adductus A correctible deformity (including after a trial of casting). Following Ponseti management . Idiopathic clubfeet. Follow up at least 6 months postoperatively. Exclusion criteria were: Fixed deformities. After surgical management. Other causes of clubfeet. e.g., Arthrogryposis. 


\section{Surgical technique}

Preoperative assessment: Obtains history, basic physical exam. Screen medical studies to identify contraindications for surgery. Orders appropriate initial imaging, and laboratory studies. Perform operative consent Room Preparation: Surgical instrumentation. Room setup, and equipment. Patient positioning. Preoperative antibiotic taken preoperative, inflation of tourniquet after limb exanquation.
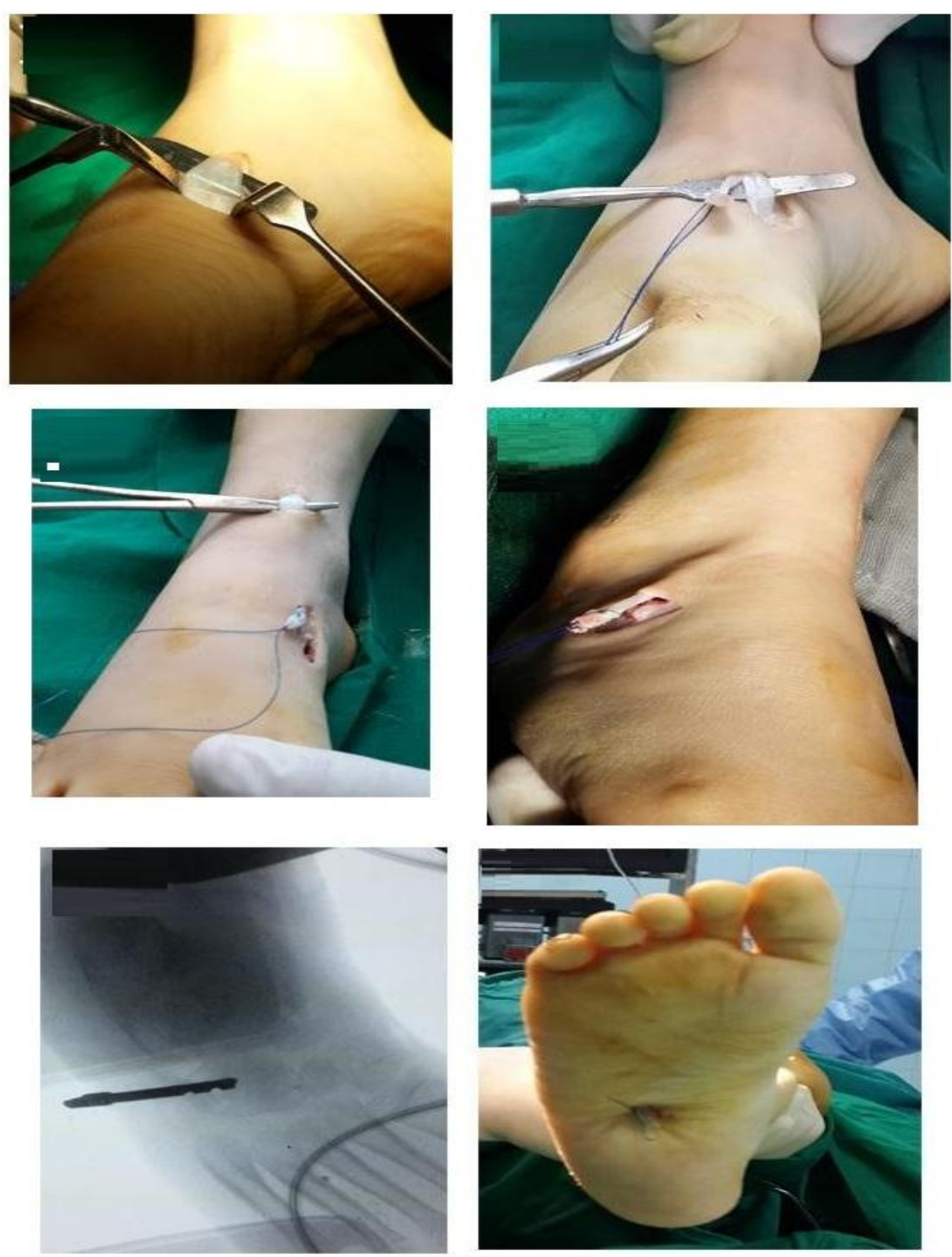

Split tibialis anterior tendon transfer

Fig. 1: Surgical technique. a) The 3 incisions. b) Isolating the tibialis anterior in wound 1. c) Splitting the lateral $1 / 2$ of the tendon. d) Isolating the tibialis anterior in wound 2. e) Retrieving the split tendon from wound 2. f) Retrieving the split tendon from wound 3. g) Drilling a hole in the cuboid. h) Tying the tendon on the sole of foot. i) Wound closure. 


\section{Evaluation methods:}

\section{Clinically:}

The clinical result , and the appearance of the foot were classified according to:

The modified rating system for functional results Excellent :130 to 150 point good:110 to 129 fair:90 to 109 poor: less than 90

\section{Radiographically}

\section{Anteroposterior standing Radiography}

Anterior talocalcaneal angle (Kite's angle) (TCA1)

Anterior talo first metatarsal angle (TFMA1)

\section{RESULTS}

\begin{tabular}{|c|c|c|}
\hline Age & N & $\%$ \\
\hline Less than 5 & 9 & 45 \\
\hline More than 5 & 11 & 55 \\
\hline Total & 20 & 100 \\
\hline
\end{tabular}

Table 1: Age groups of patients participating in the study.

Patients age ranged from 3 years to 9 years at the time of the operation with the mean age was (6).

\begin{tabular}{|c|c|c|}
\hline $\begin{array}{c}\text { Modified rating } \\
\text { system }\end{array}$ & N & $\%$ \\
\hline Excellent & 13 & $65 \%$ \\
\hline Good & 7 & $35 \%$ \\
\hline Fair & 0 & 0 \\
\hline Poor & 0 & 0 \\
\hline Total & 20 & 100 \\
\hline $\begin{array}{c}\text { Modified rating } \\
\text { system }\end{array}$ & $\begin{array}{c}\text { Pre } \\
\text { TATT }\end{array}$ & $\begin{array}{c}\text { Post } \\
\text { TATT }\end{array}$ \\
\hline Excellent, 130-150 & - & 13 \\
\hline Good, 110-129 & 10 & 7 \\
\hline Fair, 90-109 & 5 & 0 \\
\hline Poor, less than 90 & 5 & 0 \\
\hline Total & 20 & 20 \\
\hline
\end{tabular}

Table 2: Functional end results.

The functional results were classified as excellent in thirteen patients (65\%), good in seven patients (35\%), with no fair or poor results. the unsatisfactory included the fair results , and the poor results while satisfactory results including excellent and good results. Thus, satisfactory results were found in 20 patients $(100 \%)$, and no unsatisfactory ones.

\begin{tabular}{|c|c|c|c|c|c|c|c|}
\hline \multirow[b]{3}{*}{$\begin{array}{c}\text { Pre- } \\
\text { operative }\end{array}$} & \multicolumn{5}{|c|}{ Modified rating system } & \multicolumn{2}{|c|}{$\begin{array}{c}\text { Paired t- } \\
\text { test }\end{array}$} \\
\hline & \multicolumn{2}{|c|}{ Range } & $\begin{array}{c}\text { Mea } \\
\mathbf{n}\end{array}$ & \pm & SD & $\mathbf{T}$ & $\begin{array}{c}\text { P- } \\
\text { value }\end{array}$ \\
\hline & 70 & 125 & 99.5 & \pm & $\begin{array}{l}15 . \\
89 \\
\end{array}$ & & \\
\hline 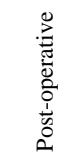 & בิ & $\stackrel{8}{n}$ & 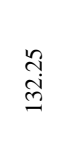 & \pm & 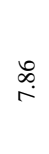 & $\begin{array}{l}\text { 京 } \\
\text { I }\end{array}$ & $\begin{array}{l}\bar{\Xi} \\
\stackrel{\leftrightarrow}{v}\end{array}$ \\
\hline
\end{tabular}

Table 3: Functional end results, and the modified rating system.
Results based on the modified rating system for functional results revealed that there is significant improvement of the final results. The mean preoperative score was 94.45 , and the mean postoperative score was 135.8 points

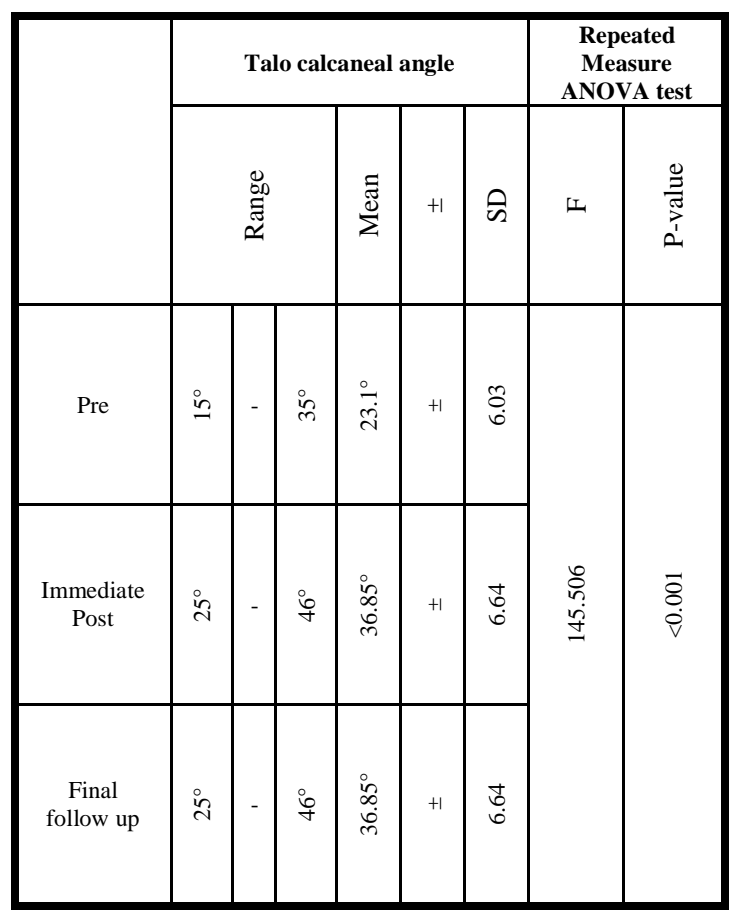

Table 4: Anterior talo calcaneal angle.

There was significant improvement of the anterior talo calcaneal angle at the final follow up $(P<0.001)$. The mean preoperative talo calcaneal angle was $23.1^{\circ}$, and the mean postoperative angle was $36.85^{\circ}$, and in final follow- up was $36.85^{\circ}$

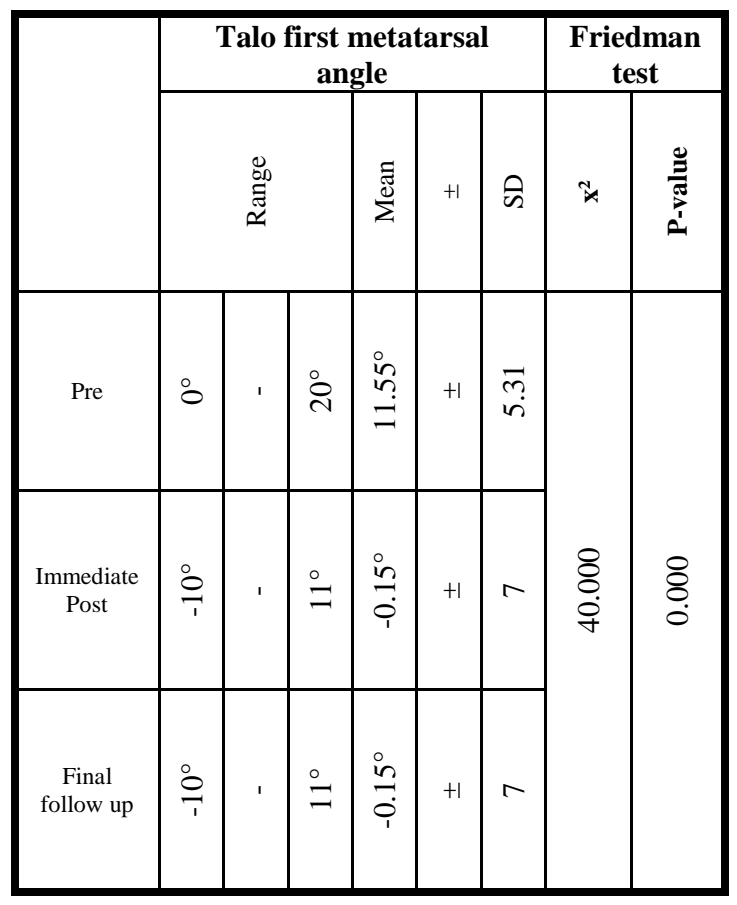

Table 5: Anterior talo first metatarsal angle. 
There was significant improvement of the anterior talo first metatarsal angle at the final follow up. The mean preoperative talo first metatarsal angle was $11.55^{\circ}$, and the mean immediate postoperative angle was -0.15 , and the final follow up was $-0.15^{\circ}$.

\begin{tabular}{|c|c|c|c|c|c|c|}
\hline \multirow{2}{*}{$\begin{array}{c}\text { Percutaneous } \\
\text { Achilles } \\
\text { tenotomy }\end{array}$} & \multicolumn{6}{|c|}{ Modified rating system } \\
\cline { 2 - 7 } & Excellent & \multicolumn{2}{|c|}{ Good } & Total & $\begin{array}{c}\text { Chi- } \\
\text { square }\end{array}$ \\
\cline { 2 - 7 } & $\mathbf{N}$ & $\mathbf{N}$ & $\mathbf{N}$ & $\mathbf{N}$ & $\begin{array}{c}\text { P- } \\
\text { value }\end{array}$ \\
\hline Yes & 10 & $50 \%$ & 5 & $25 \%$ & 15 & 0.787 \\
\hline No & 3 & $15 \%$ & 2 & $10 \%$ & 5 & \\
\hline Total & 13 & 65 & 5 & 35 & 20 & \\
\hline
\end{tabular}

Table 6: Percutaneous Achilles tenotomy and functional end results.

\section{Case Presentation}

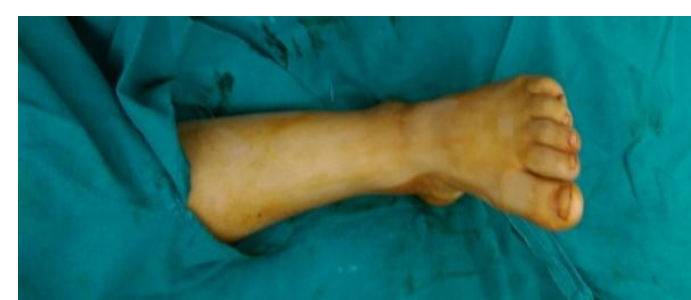

Fig. 2: Preoperative clinical appearance of the foot.

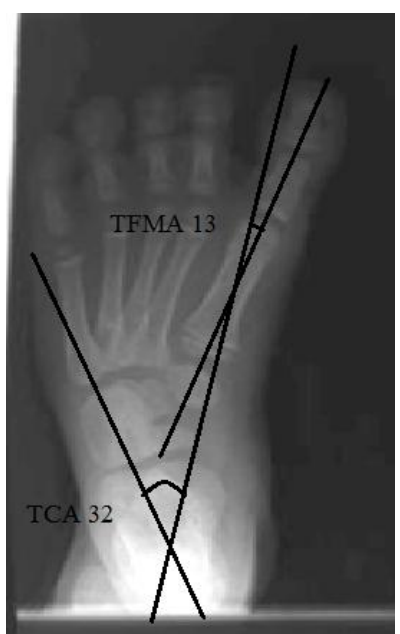

Fig. 3: x-rays of the foot Preoperatively.

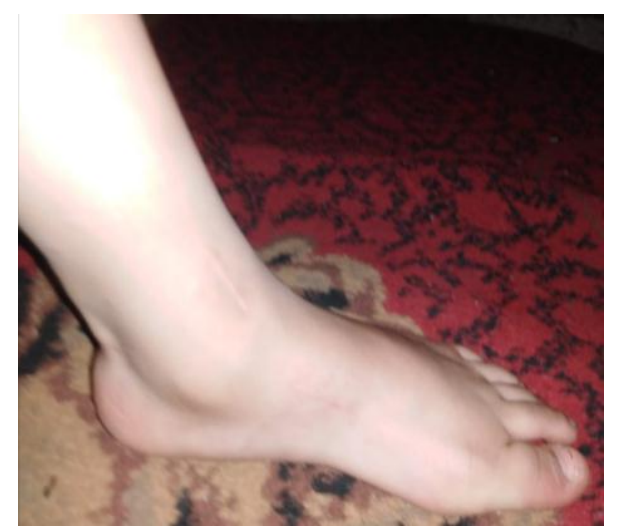

Fig. 4: clinical appearance of foot Postoperatively.

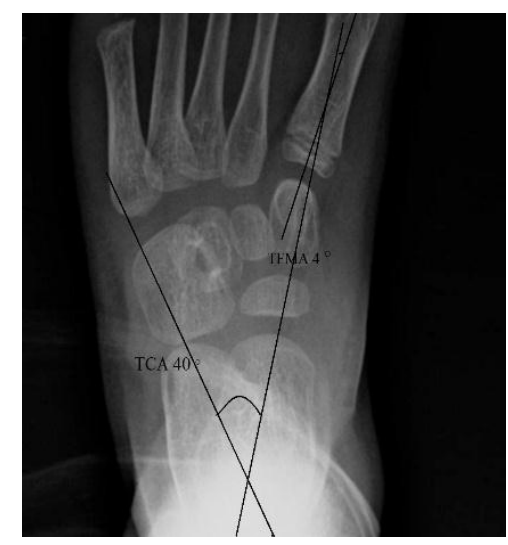

Fig. 5: Postoperative x-rays of the foot.

\section{DISCUSSION}

This relapse can occur after a Ponseti technique due to brace wear non complianc, muscular imbalance, or inadequate correction of the original deformity ${ }^{10}$. low incidence of recurrence ${ }^{7-10}$ reported after transfer of tibialis tendon with plantar loading improvement, muscle balance restorement and patient satisfaction.

In the present study, the recurrence of the club foot took place most usually between 2.5 ,and 5 years of age. Regarding the procedure timing the average age was 6years, rang 3-9 years. 20 patients with 20 feet were operated , and assessed by functional rating system 13 patients with excellent result, 7 patients with good result, no fair or poor result. 7 patients operated by split tendon transfer ,and 13 patient operated by total tendon transfer. Regarding the techniques ,and sites of tendon reinsertion, the operations were performed through Ponseti, and Smoley technique in case of full tendon transfer 7 patients above extensor retinaculum , and 3 patient underneath the retinaculum to the third cuniform. Regarding the technique of split transfer we used Hoofer technique, the tendon passes above the extensor retinaculum , and the most medial part of the tendon has been transferred into either peroneus Tertius ( 2 cases) or cuboid bone (5 cases). We have been done tenotomy of achillas tendon in 15 cases also we have been done release of the plantar fascia in 3 cases. We had 2 groups of patients group I (7 patients) with split tendon transfer cases, group II (13 patients) with full tendon transfer,preoperatively according to modified rating system,no excellent cases 10 good cases , 5 fair cases , 5 poor cases.

According to post operative modified rating system, 13 excellent cases , 7 good cases.

In the present study; most of our patients restored muscle balance with subsequent correction of dynamic supination. However statistically there was no significant relation between both groups. So there is no preference between split or full TATT. Moreover, our data showed that TATT is a good method of correcting relapsed club foot deformity. However, there is no significant difference in the result by either split or full transfer, and the selection of the procedure depend on surgeons preference. The 
range of motion, the mean preoperative subtalar joint inversion-eversion arc was 32.5 -degree + SD 4.2 the average decrease in the inversion was 3.5 degree, the average increase in eversion was 2.07. The foot evaluated radiographically postoperative by TCA ,and TFMA. Preoperative mean AP talo calcaneal angle was $23.1^{\circ}$ range $15-35^{\circ}$, postoperative mean AP talo calcaneal angle was $36.85^{\circ}$ range $27^{\circ}-45^{\circ}$. Loosing of the tendon in the transferred site developed, in one patient the cause was non suturing the tendon to the periosteum of the lateral cuniform but avoided in the subsequent cases by tendon suturing into the periosteum of the lateral cuneiform.

In the same manner cuboid or fifth metatarsal tendon transfer should be avoided as can be resulted in overcorrection so should be avoided in full tendon transfer, but in split transfer we can transfer the tendon to peroneus tertius or the cuboid bone Thompson et al. ${ }^{11}$

By the same way the effect of transfer tibialis anterior tendon was supported by the results of the study done in 2015 which confirmed that transfer of the full tibialis anterior tendon subcutaneously to the lateral cunieform in line with the third metatarsal effectively corrects relapsed club foot as well as rebalances the foot with more severe relapsed or recurrent deformities. By the same manner, followup studies of patients treated by the Ponseti method reported that 38 of 71 feet (54\%) go to transfer of tibialis anterior tendon ${ }^{11}$.

Kuo et al in 200112 reported that the average age of surgery between 4 to 8 years this allows the growth of tarsal bone with corrected position.

Ezra et al in 200013 suggested that spontaneous improvement was expected, the operation performed not before age of 3 years,and after 2 years of independent walking, 27 patient treated by full tendon transfer the average age was 3-10.5.

By the same way 2015, Knutsen ,and colleagues' original research on 10 cadavers provide novel findings on the three TATT techniques , and recommendations for use depending on the dynamic deformity , and weakness of the peronei. They supported that from neutral to maximum ankle dorsiflexion, the Ponseti transfer provided better forefoot supination and subtalar valgus motion than the other transfers. data suggested that full tendon transfer simpler than split transfer with better result in the management of a relapsed clubfoot deformity. ${ }^{14}$

Another study in 2015 illustrated that in one patient loosening of transferred tendon at the transferred site developed which required tendon retransfer also reported over correction of the other foot developed. $13-15$

Ezra et al., $2000{ }^{13}$ performed full transfer of tendon through Ponseti tow incision technique transferred the tendon to the lateral cuniform with no reported complication similar to most cases in the present study.

Kuo et $\mathrm{al}^{13} \mathrm{al}$ in their work mentioned that the senior author changed preference for the procedure from full transfer to split transfer due to tow complication in the full transfer patients, in one patient the transferred tendon loosened at the transferred site ,and the other foot was overcorrected, which required to retransfer of the tendon back to the medial side of the foot. It does not imply that the full is an inferior procedure.

Garceau ${ }^{10}$ originally passed the transferred tendon under the annular ligament, we preferred to pass the tendon under the retinaculum.

Lampasi et al in ${ }^{16}$ reported the mean angle between the talus , and first metatarsal on AP view 17. ${ }^{\circ} .5(-15$ to 46$)$ in the postoperative films , and 1.6 ( -18 to 30$)$ at follow up There was no statistically significant (p.0.05) variation between the postoperative ,and follow up measurement of talo calcaneal angle in the AP view (mean variation -0.6(-16 to 12 ).

In relation to our study 2009, A similar study included both surgically treated , and conservative patients groups, they used a modified functional rating score system of 150 points. They classified the score rating as: excellent 130-150, good 110- 129, fair $90-109$,and poor $<90$ points. All the patients had a postoperative score 40 points higher than their preoperative score , and were rated two classes higher than their preoperative one ${ }^{17}$.

In the same manner 2016, another study about changes in plantar pressure, foot motion after transfer of tibialis anterior tendon for recurrent clubfoot, and gait analysis performed six months postoperatively after surgery showed improvement. ${ }^{17}$

\section{CONCLUSION}

Tibialis anterior transfer has to be effective procedure in relapsed deformity correction ankle, muscle function of children, range of motion of foot, improved with either full or split tendon transfer.

No significant difference in the result by either split or full, and the selection of the procedure depend on surgeons preference. Non-compliance to foot abduction orthosis (FAO) was the most common cause of relapsed club foot.

\section{REFERENCES}

1. Gray K, Pacey V, Gibbons P, et al. Interventions for congenital talipes equinovarus (clubfoot) (Review). 2014;(8).

2. Garceau GJ. Anterior tibial tendon transposition in recurrent congenital club-foot. J Bone Jt Surg [Internet]. The Journal of Bone, and Joint Surgery, Inc.; 1940 [cited 2014 Dec 9]; 22(4):932-6.

3. Ponseti IV and EN S. Congenital Club Foot: The Results of Treatment. J Bone Jt Surg Am. 1963; 45: 261-344.

4. Kuo KN, Hennigan SP and Hastings ME. Anterior Tibial Tendon Transfer in Residual Dynamic Clubfoot Deformity. J Pediatr Orthop [Internet]. 2001; 21(1):35-41. 
5. Farsetti $\mathrm{P}$, Caterini R, Mancini F, et al. Anterior Tibial Tendon Transfer in Relapsing With a Different Protocol. 2006; 26(1):83-90.

6. Thompson GH, Hoyen H, Barthel T. Tibialis anterior tendon transfer after clubfoot surgery. Clin Orthop Relat Res [Internet]. 2009; 467(5):1306-13.

7. Garceau GJ. Anterior tibial tendon transposition in recurrent congenital club-foot. J Bone JointSurgAm. $1940 ; 22: 932-6$

8. Ezra E, Hayek S, Gilai AN, et al. Tibialis anterior tendon transfer for residual dynamic supination deformity in treated club feet. $J$ Pediatr Orthop $B$. 2000; 9:207-11.

9. Knutsen AR, Avoian T, Sangiorgio SN, et al. How do different anterior tibial tendon transfer techniques influence forefoot , and hindfoot motion? Clin Orthop Relat Res .2015; 473:1737-43.

10. Lampasi M, Bettuzzi C, Palmonari M et al. Transfer of the Tendon of Tibialis Anterior in Relapsed Congenital Clubfoot: long out come in 38 Feet. The Journal of Bone and Joint Surgery. British, 2010; 92: $277-83$

11. Ezra E, Hayek S, Gilai AN, et al. Tibialis anterior tendon transfer for residual dynamic supination deformity in treated club feet. $J$ Pediatr Orthop B. 2000; 9:207-11.

12. Kranzl A, Mindler G and Radler $\mathrm{CH}$. Changes in foot motion , and plantar pressure after tibialis anterior tendon transfer for clubfoot recurrence. $j$ Gait \& Posture 49S. 2016; 106. 